\title{
KESEHATAN ORGAN INTIM KEWANITAAN
}

Octa Dwienda R,SKM, M.Kes

STIKes Hang Tuah Pekanbaru

Email: octadwienda@htp.ac.id

\begin{abstract}
Organ cleanliness is important to maintain, because germs are easy to enter and cause disease in the ducts, Lack of maintaining cleanliness of external genital organs such as frequent use of feminine cleansing soap, rarely changing sanitary napkins during menstruation, use of fragrances in the pubic area and often allowing intimate organs to be wet are some of the factors that cause the occurrence of vaginal discharge. This counseling aims to see an overview of information regarding the health of female organs. The results of this counseling show that most of the students at SMPN 1 Pandau have extraordinary knowledge about the health of female organs.
\end{abstract}

Keywords: counseling, health of female organs

\begin{abstract}
ABSTRAK
Kebersihan organ genetelia penting untuk dijaga, karena kuman mudah untuk masuk dan meyebabkan penyakit pada saluran reproduksi, Kurangnya menjaga kebersihan organ genitalia eksterna seperti seringnya penggunaan sabun pembersih kewanitaan, jarangnya mengganti pembalut saat menstruasi, penggunaan alat pewangi didaerah kemaluan serta seringnya membiarkan organ intim dalam keadaan basah merupakan sebagian faktor penyebab terjadinya keputihan. penyuluhan ini bertujuan untuk mengetahui gambaran penyuluhan mengenai kesehatan organ kewanitaan. Hasil penyuluhan ini menunjukkan sebagian besar siswi SMPN 1 Pandau mempunyai pengetahuan yang luar biasa tentang kesehatan organ intim kewanitaan.
\end{abstract}

\section{Kata Kunci: penyuluhan, kesehatan organ intim kewanitaan}




\section{PENDAHULUAN}

Kebersihan organ genetelia penting untuk dijaga, karena kuman mudah untuk masuk dan meyebabkan penyakit pada saluran reproduksi, contohnya menjaga kebersihan di saat menstruasi pembuluh darah melebar sihingga memudahkan kuman masuk, keluhan yang dirasakan saat sedang menstruasi adalah terasa gatal yang diakibatkan oleh tumbuhnya jamur kandida yang akan tumbuh pada saat menstruasi (Sarwono, 2010).

Sudah banyak penelitian yang dilakukan terkait dengan kebersihan, sikap,pengetahuan dalam menjaga kebersihan organ reproduksi luar pada remaja putri.

Penelitian yang dilakukan di SLTP Jakarta timur (2003) mendapatkan hasil,sebagian besar siswi remaja di putri memiliki pengetahuan yang minim mengenai kebersihan organ reproduksi 93,4\%. Dari hasil penelitian yang dilakukan di SMA Negeri 2 Semarang 2008 sebanyak 96\% Remaja putri mengalami keputihan (Rabita, 2010 ).

Fenomena yang terjadi pada sebagian anak SMP dan SMA yang tidak paham mengenai kesehatan reproduksi, disamping itu mereka sama sekali belum pernahmendapatkan pelajaran atau informasi khususnya mengenai kesehatan reproduksi remaja. Disisi lain, sudah banyak dijumpai remaja yang sudah berpacaran dan tentu saja pada masa-masa tersebut adalah masa yang rentan akan terjerumusnya pada hal-hal yang merugiakan siswa SMP dan SMA.

Pemerintah berupaya untuk mengatasi msalah tersebut dengan melakukan upaya preventatif dengan cara penyuluhan kesehtan dan pendididkan kesehatan yang melibatkan semua tenaga kesehtan khususnya perawat. Perawat adalah suatu tenaga kesehatan yang bertugas membantu, melayani dan memberikan pendidikan kepada masyarakat khususnya remaja. Peran perawat dilakukan untuk membantu klien dalam meningkatkan pelayanan kesehatan, gejala penyakit, bahkan tindakan yang akan diberikan, sehingga masyarakat diharapkan terjadi perubahan perilaku setelah diberikan pendidikan kesehatan (Aulia, 2014).

Untuk mengatasi masalah kesehatan reproduksi pada remaja, Pendidikan kesehatan tentang masalah kesehatan alat reproduksi menjadi bagian penting dalam pelaksanaan kesehatan reproduksi. Ini disebabkan berdasarkan data yang ada sekitar 70\% wanita di Indonesia mengalami masalah kebersihan organ genitalia eksterna. Hal ini menandakan masih minimnya wanita 
yang memiliki kesadaran untuk menjaga kesehatan dirinya sendiri (Depkes, 2004).

Kurangnya menjaga kebersihan organ genitalia eksterna seperti seringnya penggunaan sabun pembersih kewanitaan, jarangnya mengganti pembalut saat menstruasi, penggunaan alat pewangi didaerah kemaluan serta seringnya membiarkan organ intim dalam keadaan basah, misalnya setelah buang air kecil tidak dikeringkan merupakan sebagian faktor penyebab terjadinya keputihan (Iswati, 2010).

\section{METODE KEGIATAN}

Metode pengabdian masyarakat ini dilaksanakan dalam bentuk penyuluhan dengan mengangkat tema " Kesehatan Organ Intim Kewanitaan " dengan memberikan ceramah langsung dan brosur berisi materi dan gambar yang menarik serta Tanya jawab seputar kesehatan organ intim kewanitaan, manfaat menjaga kesehatan organ kewanitaan, mengetahui beberapa alasan setiap anggota keluarga harus membersihkan organ kewanitaan menggunakan air bersih, cara menjaga kesehatan organ kewanitaan dan hal- hal merawat organ kewanitaan secara alami agar tidak bau.

\section{HASIL DAN PEMBAHASAN}

\section{Hasil Pelaksanaan}

Kegiatan yang dilakukan dalam pengabdian kepada masyarakat ini dilaksanakan dalam beberapa tahapan yang diawali dengan pemberian penyuluhan terlebih dahulu tentang kesehatan organ intim kewanitaan, manfaat menjaga kesehatan organ kewanitaan, mengetahui beberapa alasan setiap anggota keluarga harus membersihkan organ kewanitaan menggunakan air bersih, cara menjaga kesehatan organ kewanitaan dan hal- hal merawat organ kewanitaan secara alami agar tidak bau.

Kegiatan sosialisasi kesehatan organ intim kewanitaan ini telah dilaksanakan pada tanggal 19 Desember 2018 kepada siswi SMPN 4 Pandau Siak Hulu. Berdasarkan pengamatan selama kegiatan berlangsung, kegiatan pegabdian ini memberikan hasil sebagai berikut :

Meningkatnya pengetahuan dan pemahaman remaja siswi tentang kesehatan organ intim kewanitaan, manfaat menjaga kesehatan organ kewanitaan, mengetahui beberapa alasan setiap anggota keluarga harus membersihkan organ kewanitaan 
menggunakan air bersih, cara

menjaga kesehatan organ kewanitaan

dan hal- hal merawat organ

kewanitaan secara alami agar tidak bau. Hal ini dilihat dari kemampuan remaja siswi yang mampu menjawab pertanyaan-pertanyaan yang diberikan pemateri.

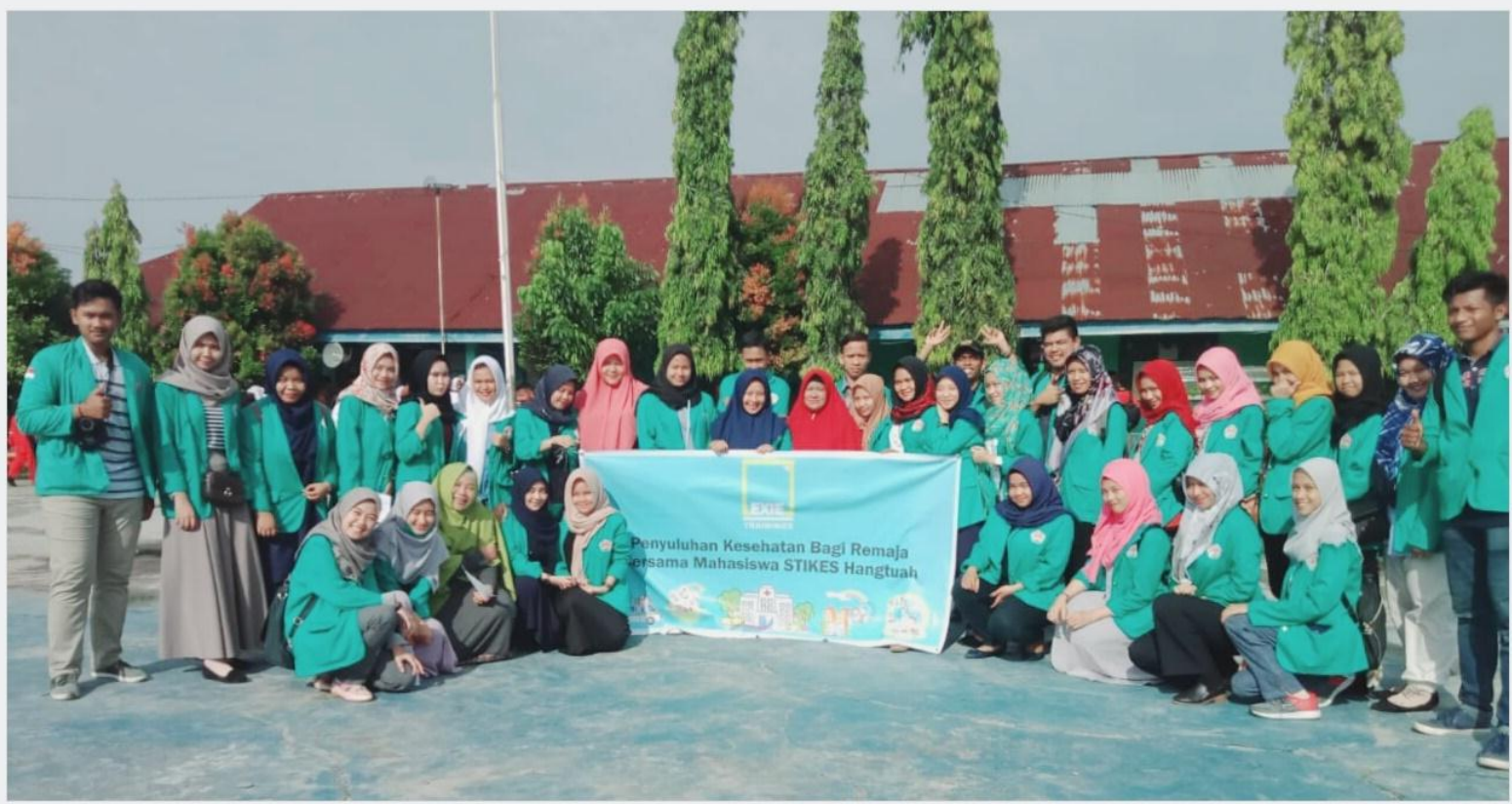

Foto Bersama Guru SMPN 4 Siak Hulu Pandau

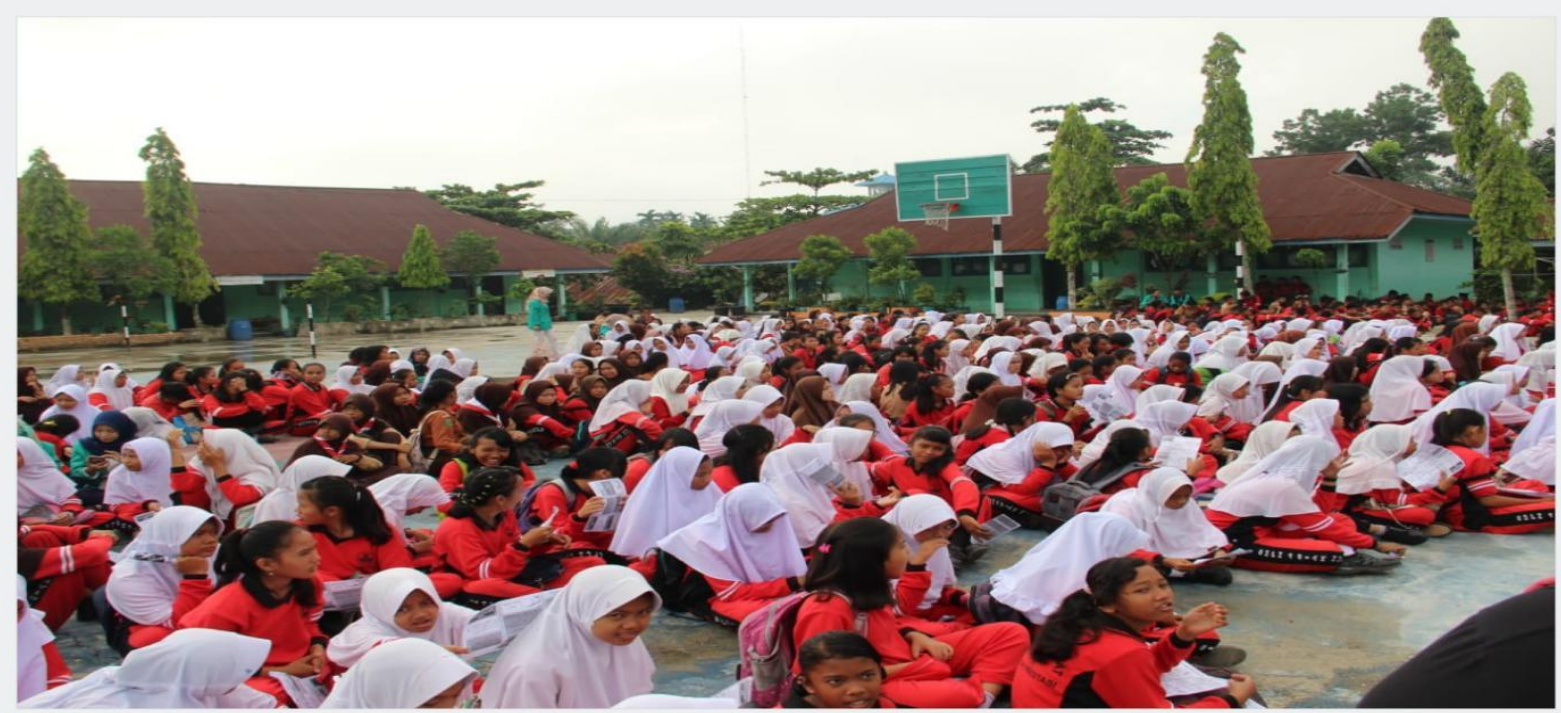

Siswi SMPN 4 Siak Hulu Pandau 


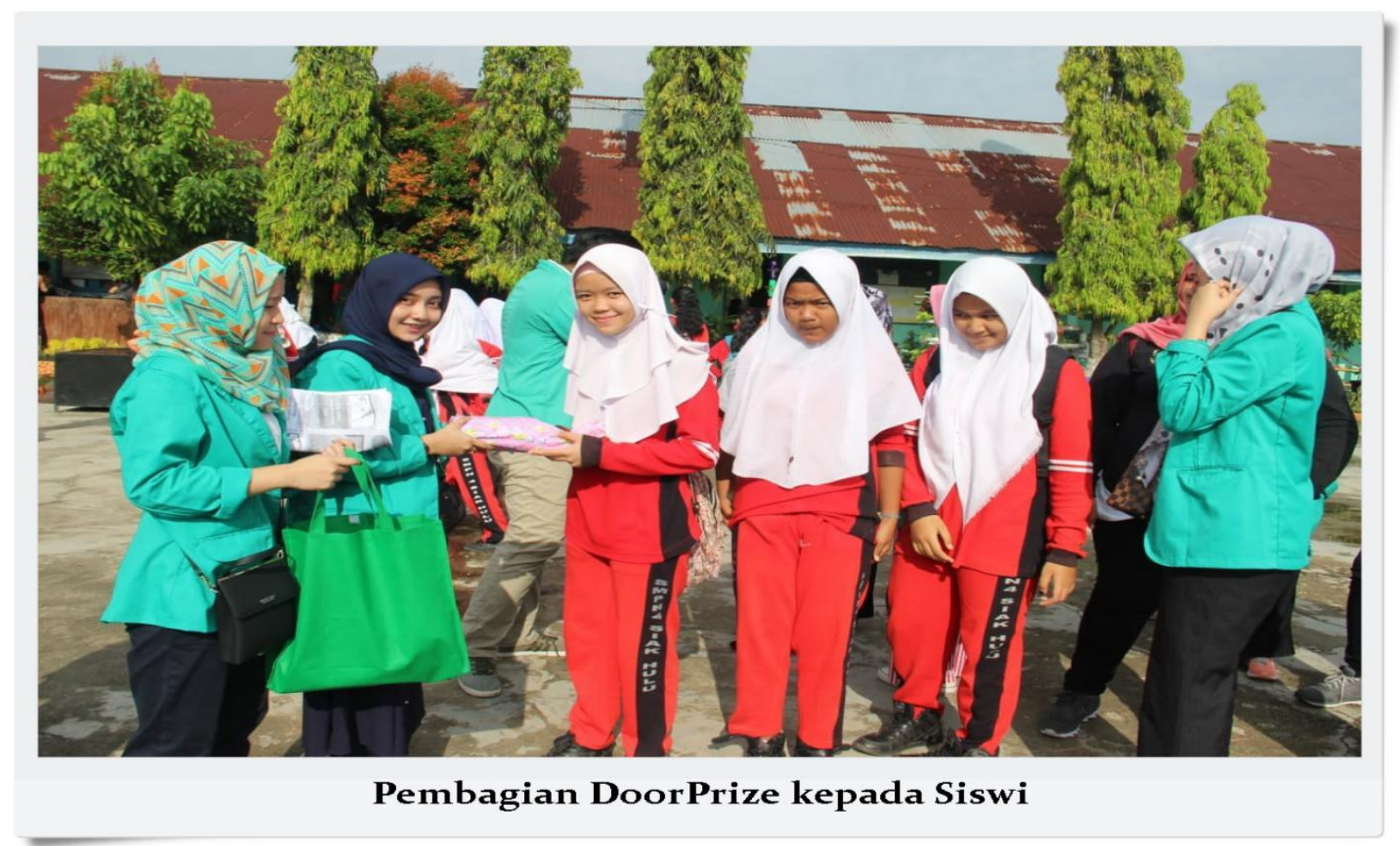

\section{Pembahasan}

Kegiatan penyuluhan tentang sosialisasi kesehatan organ intim kewanitaan di SMPN 4 Pandau Siak Hulu berjalan dengan sangat baik. Hal ini terlihat dari antusias nya para siswi hadir pada saat kegiatan berlangsung dan banyak para siswi yang bertanya menunjukkan rasa ingin tahu mereka terhadap materi yang disampaikan. Selama ini, pengetahuan siswi tentang kesehatan organ intim kewanitaan adalah masalah yang biasa baginya, tetapi setelah mendengarkan penyuluhan ini para siswi mengerti tentang pentingnya menjaga kesehatan organ intin kewanitaan, manfaat menjaga kesehatan organ intin kewanitaan, tujuan menjaga kesehatan organ intin kewanitaan, serta penanganan tentang kebiasaan sehat dalam menjaga kebersihan alat kelamin, sehingga para remaja memiliki kemandirian dalam merawat kebersihan alat kelamin, yang bisa dipraktekan setiap hari

Organ intim wanita yang sehat adalah organ intim yang bersih terbebas dari bakteri dan kuman. Masalah yang terjadi pada organ intim wanita biasanya dipicu karena kurang bisanya menjaga kebersihan organ intim.

Pentingnya menjaga kebersihan organ intim wanita. Maalah kesehatan bukan hanya sekitar kesehata 
tubuh,tulang,darah dan sendi saja. Harus memperhatikan kebersihan pada organ intim, terutama bagi seorang wanita.

\section{KESIMPULAN}

Beberapa upaya yang mungkin dilakukan sebagai tindakan antisipasi untuk memperbaiki perlaku memelihara kebersihan alat kelamin pada massa remaja tentang kebiasaan merawat alat kelamin.

$$
\begin{aligned}
& \text { Adakalanya melayani pasien } \\
& \text { remaja yang mengeluh gangguan } \\
& \text { kesehatan pada alat kelamin seperti } \\
& \text { misalnya gatal gatal, keluar keputihan } \\
& \text { yang berbau. } \\
& \text { Dalam penanganannya perlu } \\
& \text { diberikan layanan konseling tentang } \\
& \text { kebiasaan sehat dalam menjaga } \\
& \text { kebersihan alat kelamin, sehingga para } \\
& \text { remaja memiliki kemandirian dalam } \\
& \text { merawat kebersihan alat kelamin, yang } \\
& \text { bisa dipraktekan setiap hari. }
\end{aligned}
$$

\section{DAFTAR PUSTAKA}

1. Aryatiningsih, S \& Fitri, P. 2014. Promosi Kesehatan \& Ilmu Perilaku. Pekanbaru

2. Departemen Kesehatan Republik Indonesia. 2007. Housekeeping Manual, Policy \& Procedures Untuk Puskesmas. Jakarta : Departemen Kesehatan
3. Edberg, M. 2009. Buku Ajar Kesehatan Masyarakat Teori Sosial \& Perilaku. Jakarta : EGC

4. Kementerian Kesehatan Republik Indonesia. 2010. Perilaku Sederhana Berdampak Luar Biasa. Jakarta : Kemenkes RI

5. Kholid, Ahmad. 2012. Promosi Kesehatan Dengan Pendekatan Teori Perilaku, Media, Dan Aplikasinya. Jakarta : PT RajaGrafindo Persada

6. Mubarak, I \& Chayatin, N. 2009. Ilmu Kesehatan Masyarakat Teori Dan Aplikasi. Jakarta : Salemba Medika

7. Notoadmodjo, S. 2010. Promosi Kesehatan Teori \& Aplikasi. Jakarta : Rineka Cipta

8. Sadiman, Rahardjo, Haryono, \& Rahardjito. 2012. Media Pendidikan Pengertian, Pengembangan, dan Pemanfaatanya. Depok : PT RajaGrafindo Persada

9. Setiawati, S \& Dermawan. 2008. Proses Pembelajaran Dalam Pendidikan Kesehatan. Jakarta : TIM

10. https://www.alodokter.com/memahamikesehatan-dan-kebersihan-organ-intimanda 